\title{
Output voltage control of a PMSG with the DPC-SVM technique and high-order sliding mode
}

\author{
Mohammed Moumna, Rachid Taleb, Zinelaabidine Boudjema \\ Laboratoire Génie Electrique et Energies Renouvelables (LGEER), Electrical Engineering Department, \\ Hassiba Benbouali University, Chlef, Algeria
}

\begin{tabular}{|c|c|}
\hline Article Info & ABSTRACT \\
\hline Article history: & This paper aims to study the control of the output voltage of a wind turbine \\
\hline Received Oct 15, 2020 & $\begin{array}{l}\text { (WT) which is composed of a permanent magnet synchronous generator } \\
\text { (PMSG) connected to an inverter/rectifier. The first tested control on PMSG }\end{array}$ \\
\hline Revised Jun 30, 2021 & is based on the classical direct power control (CDPC); this technique uses the \\
\hline Accepted Jul 7, 2021 & $\begin{array}{l}\text { active and reactive power as a control variable. Then, to improve the quality } \\
\text { of energy and evaluate the performance of the system, we proposed a high- }\end{array}$ \\
\hline Keywords: & $\begin{array}{l}\text { order sliding mode (HOSM) with space vector modulation (SVM) to control } \\
\text { the output voltage. As a result, the proposed approach presents attractive }\end{array}$ \\
\hline DPC & features such as the chattering-free behavior of the sliding mode. This system \\
\hline HOSM & $\begin{array}{l}\text { was designed for a wind power conversion application in the case of an } \\
\text { isolated site. The computer simulations were provided to verify the validity }\end{array}$ \\
\hline PMSG & of the proposed control algorithm using the MATLAB/Simulink software. \\
\hline
\end{tabular}

This is an open access article under the CC BY-SA license.

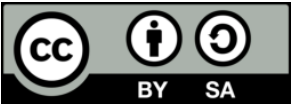

\section{Corresponding Author:}

Rachid Taleb

Laboratoire Génie Electrique et Energies Renouvelables (LGEER)

Electrical Engineering Departement

Hassiba Benbouali University, Chlef, Algeria

Email: rac.taleb@gmail.com

\section{INTRODUCTION}

In the changing world, the massive consumption of energy is tremendously expanding, which requires the search for permanent sources of energy. Ergo, renewable energy (RE) is widely demanded wich favored energy technology, along with wind energy conversion systems that are significant substantial sources. Previous studies showed that in wind energy zones (WEZs) that are based on permanent magnet synchronous generators (PMSGs) remains the most famous one. Hence, to improve the capacity of the system and the WEZ power, PMSGs were used. Actually, PMSGs were pressed into service to annihilate the med for a gearbox, which has further lowered the maintenance costs.

Most conducted researches in the framework of WEZs centralized their focus on the growth of control strategies that was founded on modern nonlinear control techniques to better control potency in order to supply and regulate active and reactive powers. Accordingly, distinct control methods, like adaptive monitoring [1], robust monitoring [2] and fuzzy logic monitoring [3] have been used for PMSG-based WEZs. On the other hand, another proposed method of control for attaining more elevated achievements, solidity, and constancy that brings about good expectation is the sliding mode control (SMC) method. The study at hand attempts to produce a high SMC method (HSMC) integrated with direct power control (DPC) using space vector modulation (SVM) (HSMC-DPC-SVM) to adjust the active and reactive powers produced by the WEZs and it was more inoculated into the grid under the constant DC link voltage $\left(\mathrm{V}_{\mathrm{dc}}\right)$. Mostly, the SMC using SVM monitors the machine side converter (MSC). 
The current study presents an analytical study of the constant DC link voltage $\left(\mathrm{V}_{\mathrm{dc}}\right)$ method. The suggested monitoring scheme is plain with a more rapid dynamic response. However, the old DPC controls bear more damages and flaws such as high active power ripple and reactive power ripple exposed to the firm conditions because of the hysteresis bauds. In former years, many studies deduced various solutions to develop the achievement of the classical DPCs strategy. For the purpose of decreasing the two powers ripple and THD value of stator current, SMC is one of the well-celebrated methods in manufacturing.

In this research, a combination of DPC strategy with SVM technique is suggested to monitor PMSG throughout the implementation of this mingling monitoring scheme, a more dynamic, elevated realization is promised; that is to say, fewer disadvantages as the high vibration in active-reactive powers. THD values of stator current, the ramification of the SMC. Then, this paper introduces a fresh scheme to make the dive performance more efficient. SVM-HSMC technique in DPC (DPC-SVM-HSMC) main features is to improve the power factor and efficiency and lower power ripples. This paper provides a comparative outlook on distinct DPC schemes, including old or classical DPC and DPC-SVM-HSMC control. The handed scheme is plainly described with more elucidating reports of its effectiveness with simulated outcomes. The mentioned scheme was obtained with MATLAB /Simulink software.

\section{SYSTEM DESCRIPTION}

This manuscript offers an exemplified diagram on the function of a PMSG system made of an adjustable wind turbine (WT) based on PMSG that throughout a convertor and DC link voltage is connected to the grid as demonstrated in Figure 1. To monitor the instantaneous active and reactive powers, the SVM is using the SMC method to monitor the grid side converter.

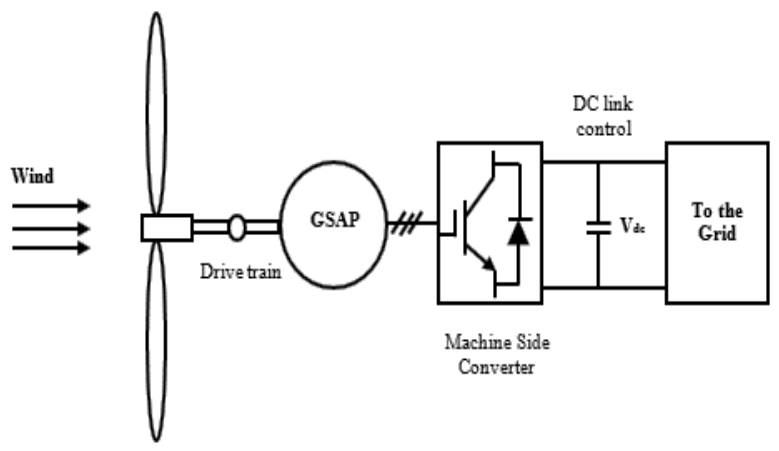

Figure 1. Permanent magnet synchronous generator (PMSG) and wind turbine (WT) structures

\subsection{Modeling of the permanent magnet synchronous generator (PMSG)}

The representation of the permanent magnet synchronous machine has consistently been the subject of different assessments. A sample of this machine in the park reference will be used. The latter is in conviction a two-phase reference, a resemblance of the three-phase reference, less complex to manage considering the way that the electrical sums create as continuous elements [4], [5]. The PMSM's given model is illustrated by the electric, magnetic and mechanical equations [6], [7]:

Voltage and stator flux expressions. In generator case, with reversing of the currents sense, we will have the electric and flux term of PMSG as pursues [5], [8]:

$$
\begin{aligned}
& \left\{\begin{array}{l}
{\left[V_{a b c}\right]=\left[R_{s}\right]\left[I_{a b c}\right]+\frac{d}{d t}\left[\Phi_{a b c}\right]} \\
{\left[\Phi_{a b c}\right]=\left[L_{s}\right]\left[I_{a b c}\right]+\left[\Phi_{e a b c}\right]}
\end{array}\right. \\
& \left\{\begin{array}{l}
V_{d}=-R_{S} \times I_{d}-\frac{d}{d t} \Phi_{d}+\omega_{r} \times \Phi_{q} \\
V_{q}=-R_{S} \times I q-\frac{d}{d t} \Phi q-\omega_{r} \times \Phi_{d} \\
\Phi_{d}=L_{d} \times I_{d}+\Phi_{e} \\
\Phi_{q}=L_{q} \times I_{q}
\end{array}\right.
\end{aligned}
$$

$\mathrm{L}_{\mathrm{d}}, \mathrm{L}_{\mathrm{q}}$ be the inductors of the stator, $\mathrm{V}_{\mathrm{d}}, \mathrm{V}_{\mathrm{q}}$ is the voltage stator, $\mathrm{I}_{\mathrm{d}}$ and $\mathrm{I}_{\mathrm{q}}$ are current stators, direct and quadratic, respectively, $\Phi_{\mathrm{e}}$ is flux per pole of the permanent magnet. Relative to the angle of the rotor rotation and after deriving the storage electromagnetic energy, the electromagnetic torque $\mathrm{C}_{\mathrm{em}}$ is expressed by [8], [9],

Output voltage control of a PMSG with the DPC-SVM technique and high-order ... (Mohammed Moumna) 


$$
C_{e m}=\frac{3}{2} P \times\left[\left(L_{d}-L_{q}\right) \times I_{d} \times I_{q}+I_{q} \Phi_{e}\right]
$$

The PMSG's dynamic equation is exemplified,

$$
C_{m}-C_{e m}-f \Omega=j \cdot \frac{d}{d t} \Omega
$$

\section{PRINCIPLE OF DIRECT POWER CONTROL (DPC)}

The traditional direct power control (DPC) relies upon the possibility of the direct torque control that is applied to electrical machines. The main aim is to directly control the powers (active and reactive ones) in a PWM rectifier [10], [11]. The switching states of the semiconductors are determined by introducing the errors between the instantaneous values of active and reactive powers with their measurements into two hysteresis comparators, with the assistance of the generator's voltage vector area location and a switching table [12], [13]. A PI controller adjusts to the DC bus voltage loop.

\subsection{Switching table}

According to each rectifier input voltage vector and the area where they are located, Table 1 offers the signs of variation of the instantaneous active and reactive powers. The selection of the sign of the active and reactive power variations independently is possible by selecting the appropriate output vector [1], [14].

Table 1. Variation of $\mathrm{p}$ and $\mathrm{q}$ as a function of the position of the vectors

\begin{tabular}{cccccccc}
\hline & $\mathrm{V}(\mathrm{k}-2)$ & $\mathrm{V}(\mathrm{k}-1)$ & $\mathrm{V}(\mathrm{k})$ & $\mathrm{V}(\mathrm{k}+1)$ & $\mathrm{V}(\mathrm{k}+2)$ & $\mathrm{V}(\mathrm{k}+3)$ & $\mathrm{V}(0,7)$ \\
\hline$\Delta \mathrm{p}$ & - & - & + & + & - & - & - \\
$\Delta \mathrm{q}$ & + & + & + & - & - & - & 0 \\
\hline
\end{tabular}

In some cases, the examination of the table shows that there are several possibilities of applying different vectors that allow us to obtain the same increase in $\Delta \mathrm{p}$ and $\Delta \mathrm{q}$. In this case, the choice that guarantees the smallest variation in power is the choice of the appropriate voltage vector. To meet this criterion, only four voltage vectors are possible: $\mathrm{v}(\mathrm{k}-1), \mathrm{v}(\mathrm{k}) \mathrm{v}(\mathrm{k}+1)$ and $\mathrm{v}(\mathrm{k}+2)[1]$.

\subsection{Instantaneous power calculation}

The pursue formulas designate the instantaneous powers:

$$
p=\operatorname{Re}\left(\bar{e} . \overline{i^{*}}\right) ; q=\operatorname{Im}\left(\bar{e} \cdot \overline{i^{*}}\right)
$$

where p, q: the instantaneous active and reactive power. e, i: voltage and current vector. * is the conjugate symbol. Therefore, to calculus the total instantaneous active and reactive powers,

$$
p=e_{a} \cdot i_{a}+e_{b} \cdot i_{b}+e_{c} \cdot i_{c} ; q=\frac{1}{\sqrt{3}}\left[\left(e_{b}-e_{c}\right) \cdot i_{a}+\left(e_{c}-e_{a}\right) \cdot i_{b}+\left(e_{a}-e_{b}\right) \cdot i_{c}\right]
$$

\subsection{Instantaneous power calculation by estimating the flux}

The instantaneous power can be calculated if the flux is used. Therefore, a flux vector in the coordinates $(\alpha, \beta)$ is generated by integrating the generator voltage. The voltage drop in the resistor is neglected [15], [16].

$$
\begin{cases}\& & \Phi_{s \alpha}=\int e_{\alpha} d t=\int\left(V_{s \alpha}-L \frac{d i_{\alpha}}{d t}\right) d t \\ \& & \Phi_{s \beta}=\int e_{\beta} d t=\int\left(V_{s \beta}-L \frac{d i_{\beta}}{d t}\right) d\end{cases}
$$

Where: $\Phi$ is the flux estimation with $\mathrm{v}$ as the converter voltage.

Taking into account that the inverter voltage is in the coordinates $\alpha / \beta$, the flux expression will be as:

$$
\left\{\begin{array}{c}
\Phi_{s \alpha}=\int\left(\sqrt{\frac{2}{3} U_{d c}}\left(S_{a}-\frac{1}{2}\left(S_{b}+S_{c}\right)\right)\right) d t-L . i_{\alpha} \\
\& \Phi_{s \beta}=\int\left(\sqrt{\frac{2}{3} U_{d c}}\left(S_{b}-S_{c}\right)\right) d t-L . i_{\beta}
\end{array}\right.
$$


from the estimated flux, we get the voltage:

$$
\bar{e}=\frac{d}{d t} \bar{\Phi}=\frac{d \Phi}{d t} e^{j w t}+j w \Phi e^{j w t}=\frac{d \Phi}{d t} e^{j w t}+j w \bar{\Phi}
$$

where: $\bar{\Phi}$ is the estimated flux vector and $\Phi$ is their amplitude.

Therefore, the instantaneous power is calculated in the coordinates $\alpha / \beta$,

$$
p=e_{\alpha} \cdot i_{\alpha}+e_{\beta} \cdot i_{\beta} ; q=e_{\beta} \cdot i_{\alpha}-e_{\alpha} \cdot i_{\beta}
$$

the derivatives of the flux amplitude are zero for balanced and sinusoidal voltages. Then, the instantaneous active and reactive power is calculated by the equation in [1], [17],

$$
p=w \cdot\left(\Phi_{\alpha} \cdot i_{\beta}-\Phi_{\beta} \cdot i_{\alpha}\right) ; q=w \cdot\left(\Phi_{\alpha} \cdot i_{\alpha}+\Phi_{\beta} \cdot i_{\beta}\right)
$$

\section{HIGH-ORDER SLIDING MODE CONTROL APPROACH}

\subsection{Principle of the sliding mode control (SMC)}

The SMC is based on holding and moving, with appropriate switching logic, the state trajectory of the system to a predetermined sliding or switching surface [2], [3]. This system is similar to a feed-forward controller that provides the control that should be applied to follow a desired, user-defined sliding surface [18]. Hence, the development of a sliding mode controller requires two steps; the first is the definition of an adequate switching surface $S$ and then the elaboration of the control law or switching logic $U$ [19], [20].

In this article, the choices of sliding surfaces are the errors between the measured and reference stator currents. The principle of this control is to drive each error to a "switching surface". Then, the following expression can be written [21], [22]:

$$
\left\{\begin{array}{l}
S_{1}=I_{\text {dref }}-I_{d} \\
S_{2}=I_{\text {qref }}-I_{q}
\end{array}\right.
$$

the principal drawback of the practical implementation of the SMC is the chattering phenomenon. The HOSM is the most effective way to cope with this problem. It influences the higher-order temporal derivatives of the sliding corrector instead of the first-order temporal derivative, in another way this technique generalizes the basic idea of the sliding mode. With conservation of the main original properties and by the operational characteristic of this approach, this technique allows the attenuation of the chattering effect [23], [24]. We used a robust high-order sliding mode strategy to ensure convergence to current references. (12) gave the sliding mode surfaces, so the expression can be written as [24], [25]:

$$
\begin{aligned}
& \left\{\begin{array}{l}
\dot{S}_{1}=\dot{I}_{\text {dref }}-\dot{I}_{d} \\
\ddot{S}_{1}=\phi_{1}(t, x)+\gamma_{1}(t, x) \dot{V}_{d}
\end{array}\right. \\
& \left\{\begin{array}{l}
\dot{S}_{2}=\dot{I}_{\text {qref }}-\dot{I}_{q} \\
\ddot{S}_{2}=\phi_{2}(t, x)+\gamma_{2}(t, x) \dot{V}_{q}
\end{array}\right.
\end{aligned}
$$

where $\varphi_{I}(t, x), \varphi_{2}(t, x), \gamma_{1}(t, x)$, and $\gamma_{2}(t, x)$ are uncertain bounded functions that satisfy the conditions:

$$
\left\{\begin{array}{l}
\phi_{1}>0,\left|\phi_{1}\right|>\lambda_{1}, 0<K_{m 1} \prec \gamma_{1} \prec K_{M 1} \\
\phi_{2}>0,\left|\phi_{2}\right|>\lambda_{2}, 0<K_{m 2} \prec \gamma_{2} \prec K_{M 2}
\end{array}\right.
$$

the increase in the required information when implementing the HOSM algorithm is the biggest problem. Indeed, it is necessary to know the $\dot{S}, \ddot{S}, \ddot{S}, \ldots ; \stackrel{(n-1)}{S}$ for the implementation of an nth-order controller. It is just necessary to have information about the sliding surface $S$, this is the exception of the super-torsion algorithm [24], [25]. Therefore, the use of this algorithm to design the proposed control approach contains two parts proposed by this HOSM controller:

$$
\left\{\begin{array}{l}
V_{d}=u_{1}+u_{2} \\
V_{q}=w_{1}+w_{2}
\end{array}\right.
$$

With: $\left\{\begin{array}{l}\dot{u}_{1}=-k_{1} \operatorname{sign}\left(S_{1}\right) \\ u_{2}=-l_{1}\left|S_{1}\right|^{\gamma} \operatorname{sign}\left(S_{1}\right)\end{array}\right.$ and $\left\{\begin{array}{l}\dot{w}_{1}=-k_{2} \operatorname{sign}\left(S_{2}\right) \\ w_{2}=-l_{2}\left|S_{2}\right|^{\gamma} \operatorname{sign}\left(S_{2}\right)\end{array}\right.$ 
the convergence of sliding manifolds to zero in finite time is ensured by gains that can be chosen,

$$
\left\{\begin{array}{l}
K_{i}>\frac{\lambda_{i}}{K_{m i}} \\
l_{i}^{2} \geq \frac{4 \lambda_{i}}{K_{m i}^{2}} \frac{K_{m i}\left(K_{i}+\lambda_{i}\right)}{K_{m i}\left(K_{i}-\lambda_{i}\right)} ; i=1,2 \\
0 \prec \gamma \leq 0.5
\end{array}\right.
$$

\section{SIMULATION RESULTS}

The examined system is showing in the block diagram in Figure 2, the objective of this control is to hold constant the voltage of DC bus (reference taken equal to $\mathrm{V}_{\mathrm{dc}-\mathrm{ref}}=600 \mathrm{~V}$ ) and impose a sinusoidal current absorption. Regarding reference tracking, power ripples, stator current harmonics distortion, and robustness against the variations of parameters, the simulation results of DPC-SVM with HSMC controller of PMSG are compared with the conventional DPC command scheme. In this section, the MATLAB/Simulink software was used to simulate three tests of the system under examination.

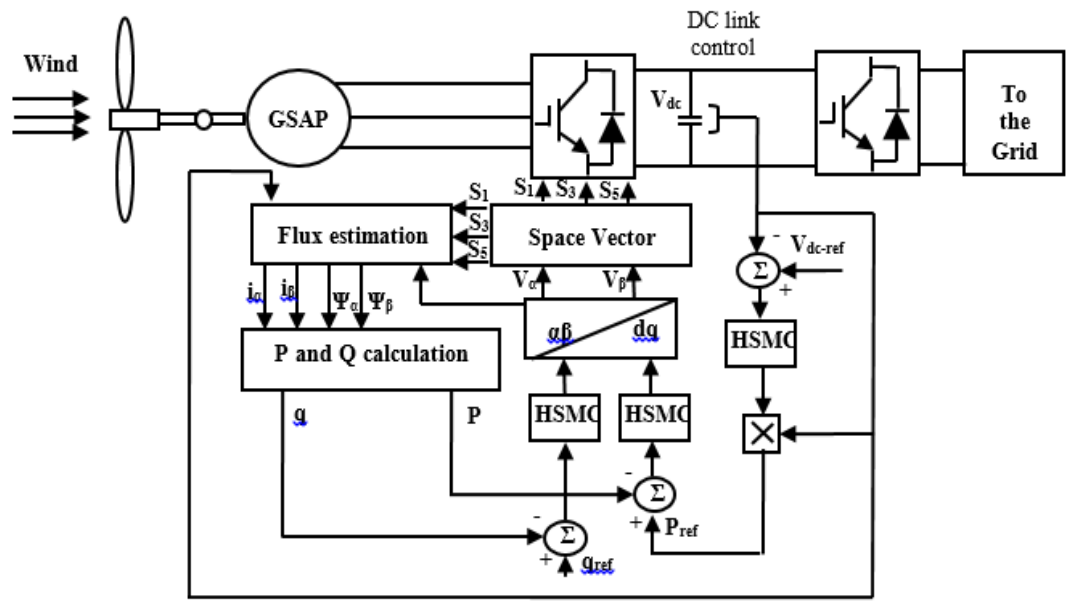

Figure 2. Block diagram of the DPC-SVM with HSMC

\subsection{Wind speed response test}

In this test, Figure 3 shows the profile of the variation in the rotor speed because of a change in wind speed. Figure 4(a)-(f) shows the response of the DC bus voltage, the active and reactive power for the conventional DPC and the proposed topology (DPC-SVM-HSMC). Despite the disturbances that are due to the variation of the rotor speed, in this case, it can be noticed that the proposed topology of the control keeps the output DC voltage at its reference, the case where it presents a fluctuation in the classical control. Moreover, compared to the classical DPC control, it can be clearly observed that the DPC-SVM-HSMC strategy reduces the ripple in the active power and the reactive power. In addition, this strategy eliminates peaks resulting from rotor speed changes (zoom).

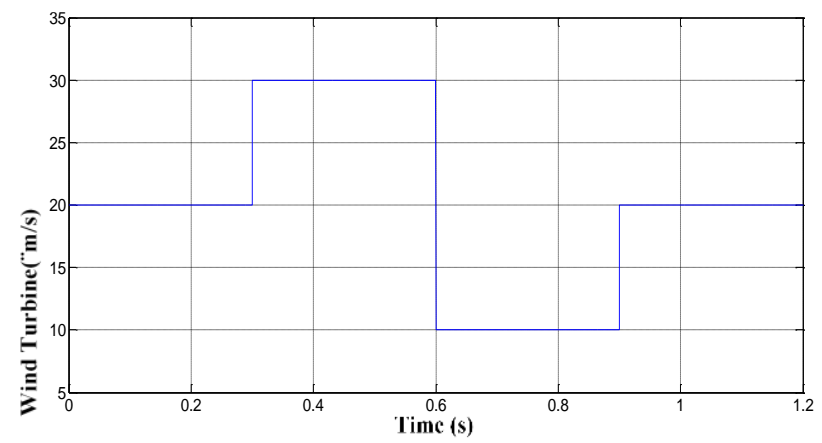

Figure 3. Wind profil 


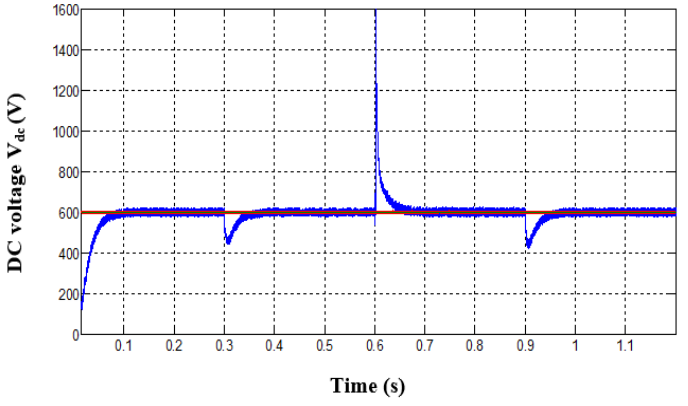

(a)

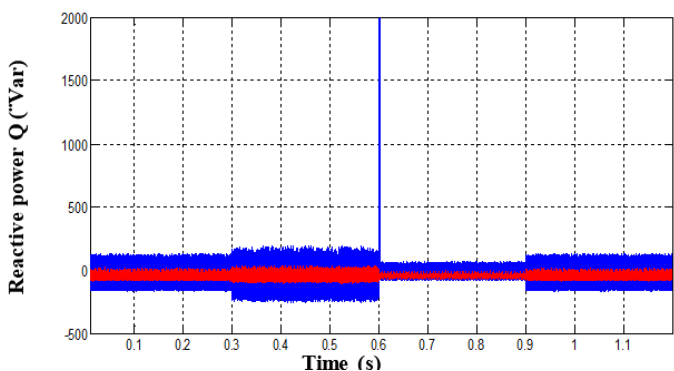

(c)

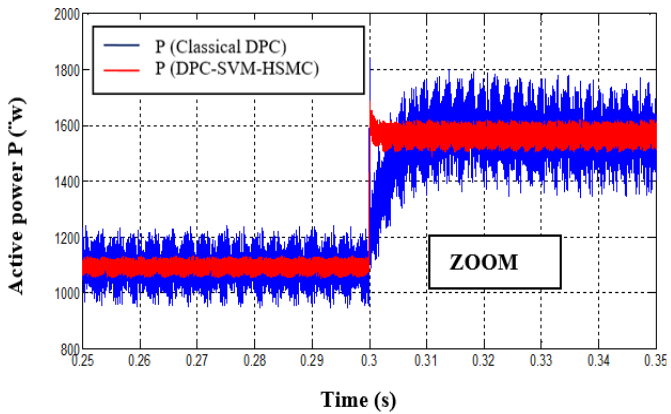

(e)

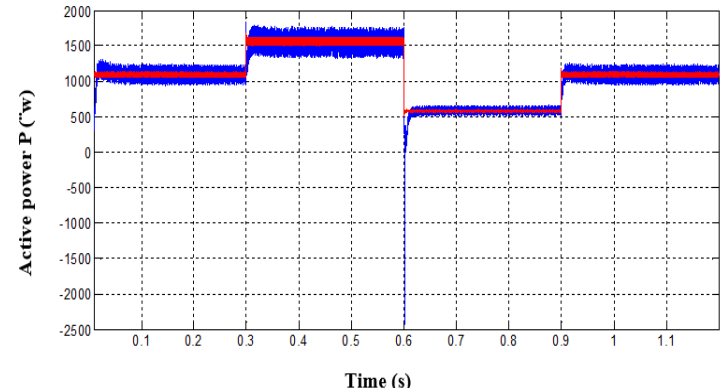

(b)

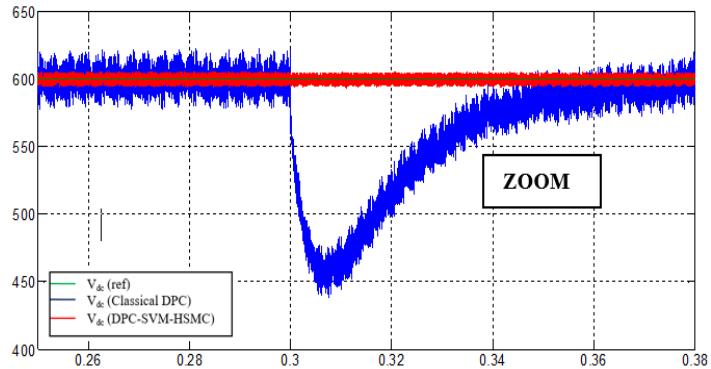

(d)

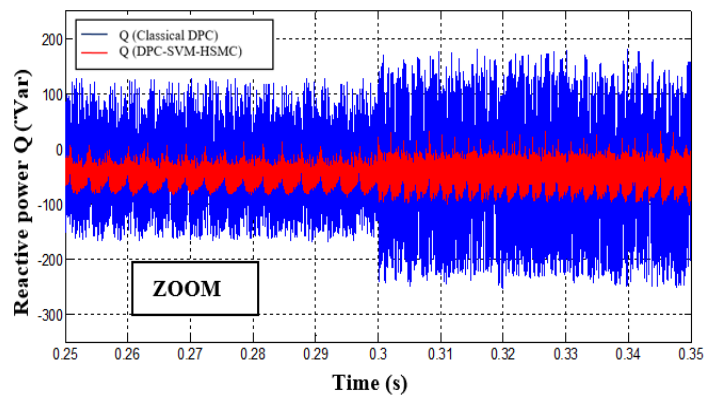

(f)

Figure 4. Wind speed response test; (a) output DC voltage; (b) active power; (c) reactive power; (d) zoom in output DC voltage; (e) zoom in active power; (f) zoom in reactive power

\subsection{Reference tracking test}

Figures 5(a) and (b) shows the second test simulation results, with a constant rotor speed, the aim is to vary the value of the output DC voltage. This last, in the case of DPC-SVM-HSMC, track almost perfectly their reference values and more rapidly than the classical DPC as shown in Figure 5. On the other hand, in Figures 6(a)-(f), the proposed control strategy reduced the ripples in the active power, reactive power and stator current compared to the classical DPC control.

Figures 7(a)-(c) shows the Lissajous shape (of the stator flux components $\Phi_{\mathrm{s} \alpha}$ and $\Phi_{\mathrm{s} \beta}$ ), the circular shape implies that the waveform is sinusoidal in both components, but the thickness of the circle means the content of harmonics in its components, this thickness is thinner in the case of the proposed strategy. For clarification, Figure 7 shows the harmonic spectrum of the stator current of the PMSG, the THD value is reduced when compared to the classical method.

\subsection{Robustness test}

In this section, we want to test the robustness of the proposed strategy, so we change the machine parameters (resistance value doubled and half of the inductances). Figures 8(a)-(f) and Figures 9(a)-(c) present the simulation results; these changes imply remarkable effects on active power, reactive power and stator current curves, this effect is more important in the case of the classical DPC control. In addition, we can also observe that the THD value of stator current has been reduced in the DPC-SVM-HSMC command, which proves the robustness of the proposed topology. 


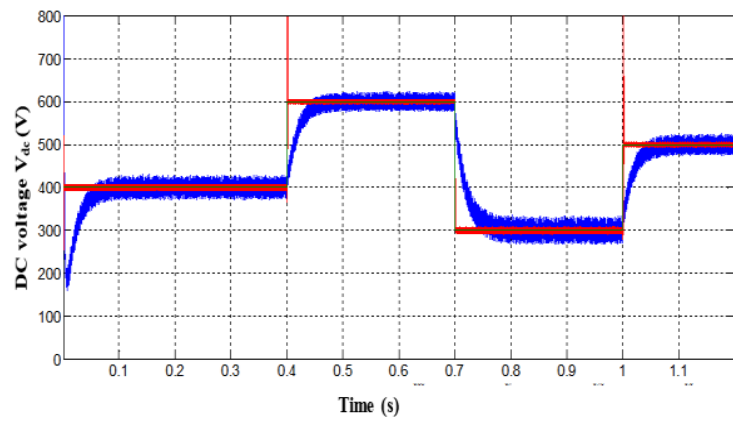

(a)

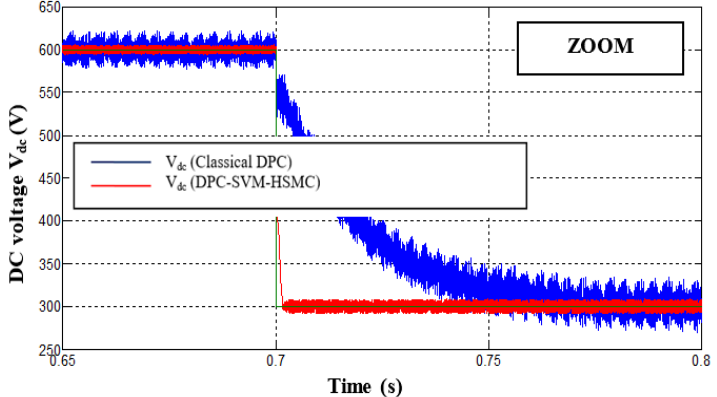

(b)

Figure 5. Reference tracking test; (a) output DC voltage and (b) zoom in output DC voltage

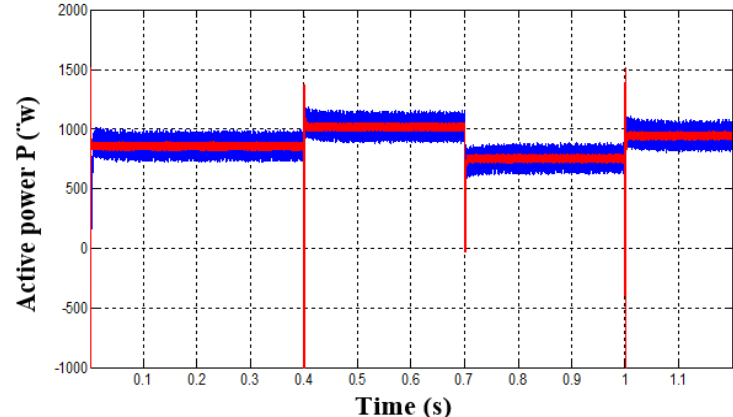

(a)

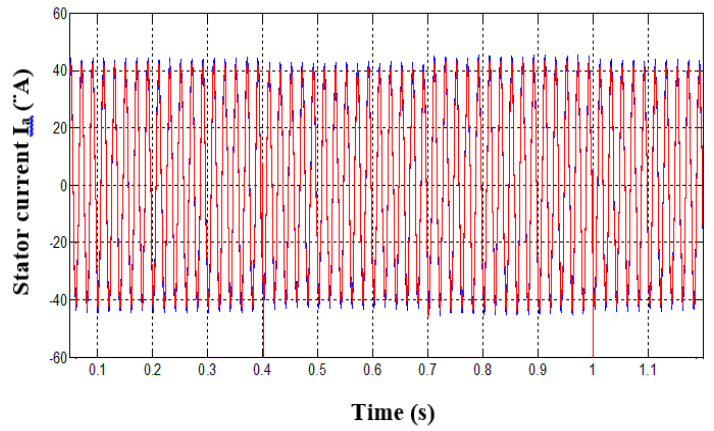

(c)

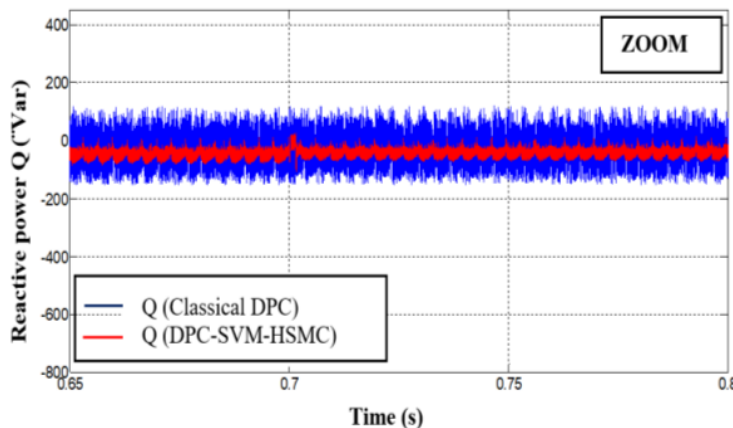

(e)

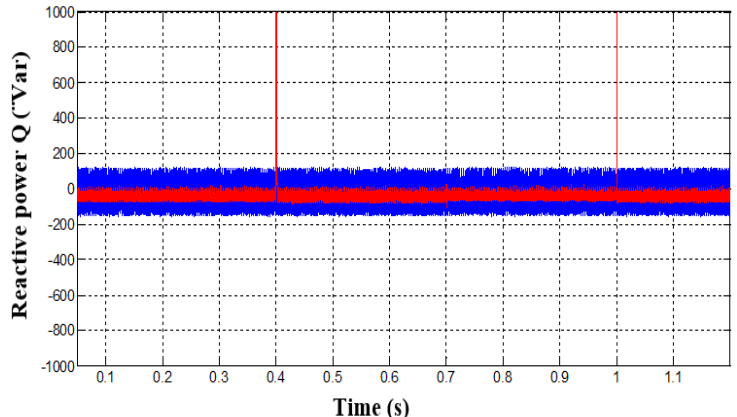

(b)

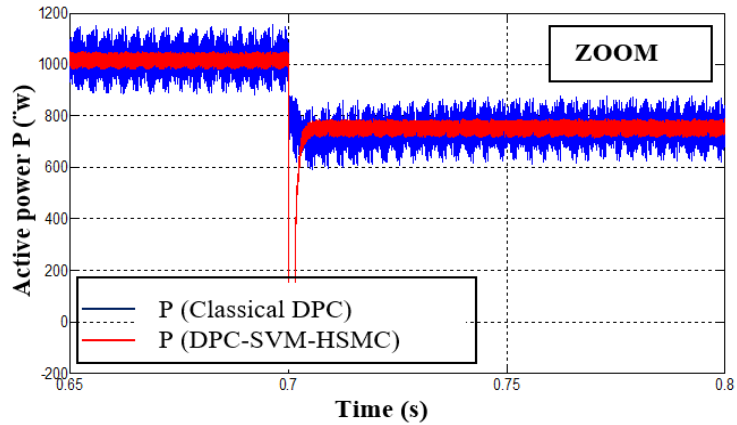

(d)

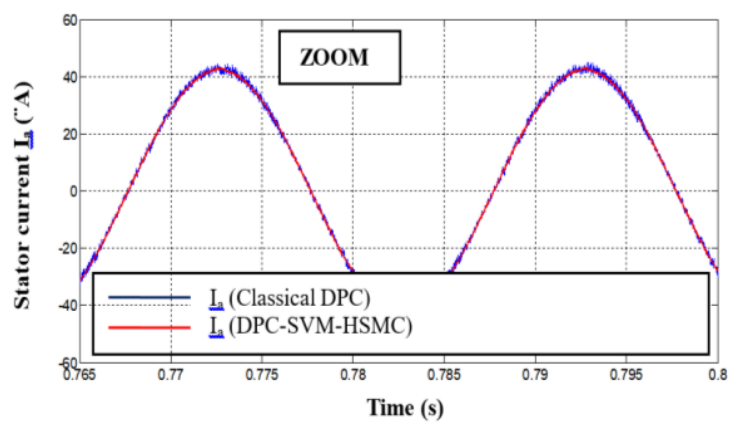

(f)

Figure 6. Reference tracking test; (a) active power; (b) reactive power; (c) stator current; (d) zoom in active power; (e) zoom in reactive power; (f) zoom in stator current 


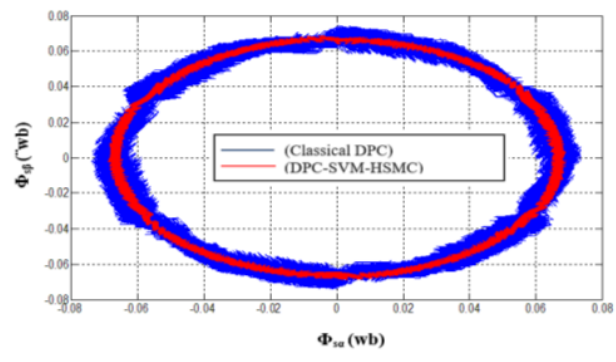

(a)

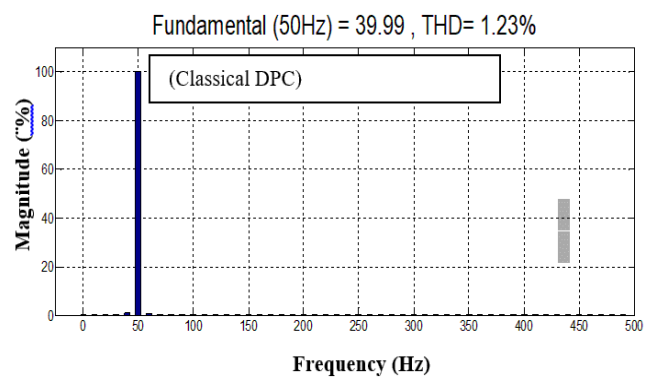

(b)

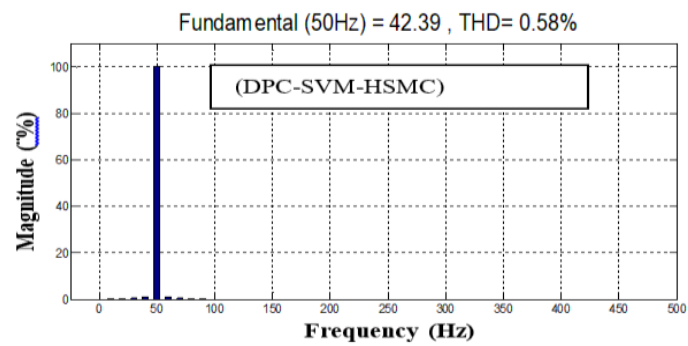

(c)

Figure 7. Reference tracking test; (a) flux in the reference frame $(\alpha, \beta)$; (b) THD of stator current for classical DPC; (c) THD of stator current for DPC-SVM-HSMC

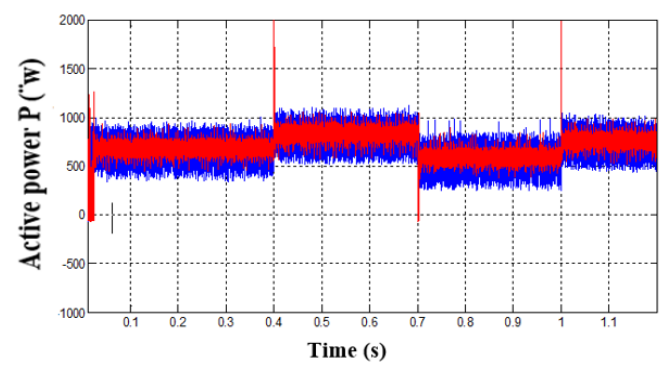

(a)

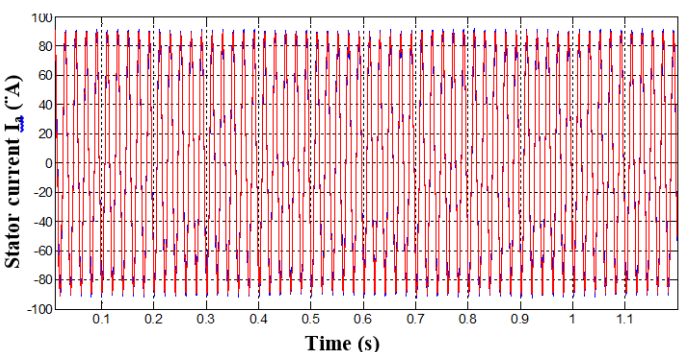

(c)

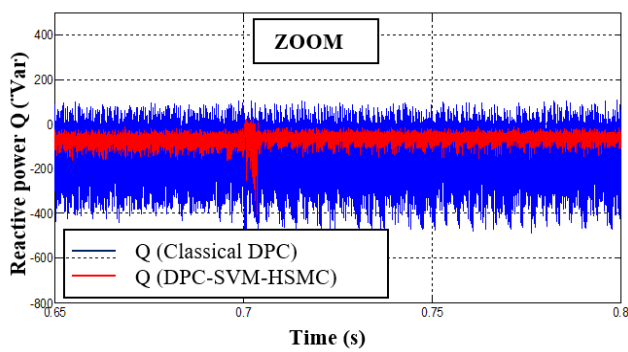

(e)

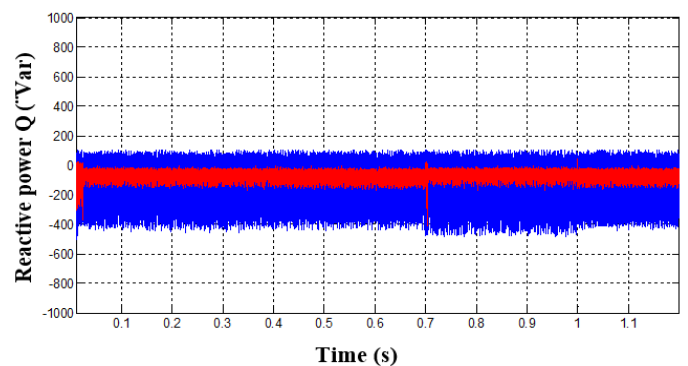

(b)

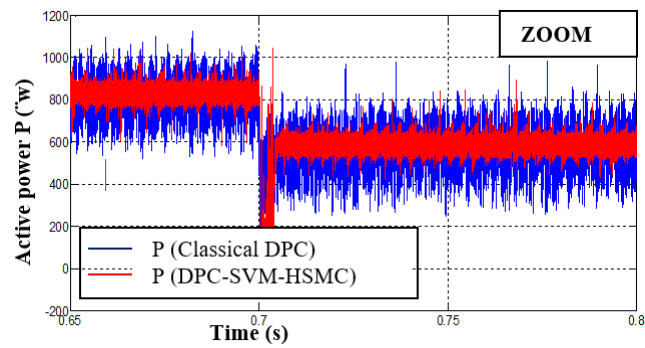

(d)

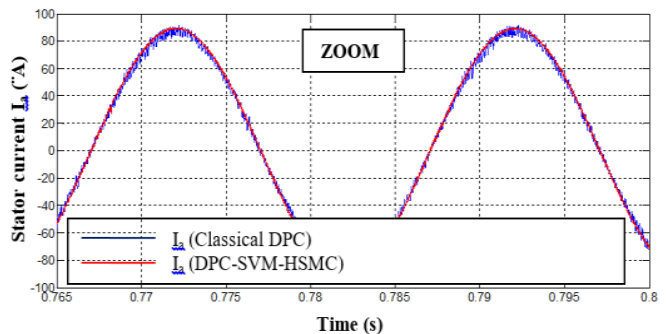

(f)

Figure 8. Robustness test; (a) active power; (b) reactive power; (c) stator current; (d) zoom in active power; (e) zoom in reactive power; (f) zoom in stator current 


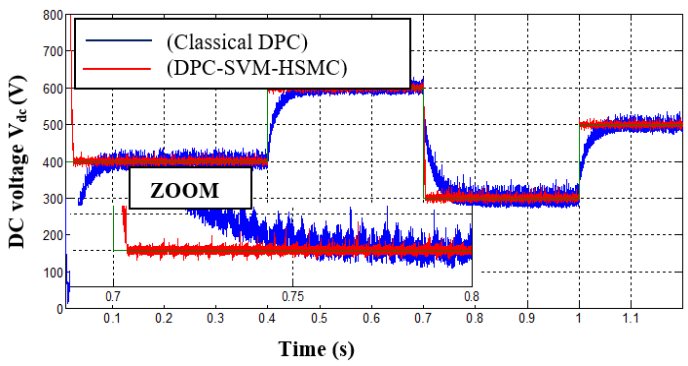

(a)

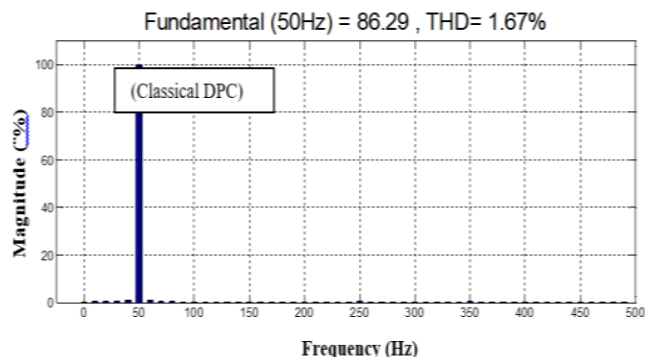

(b)

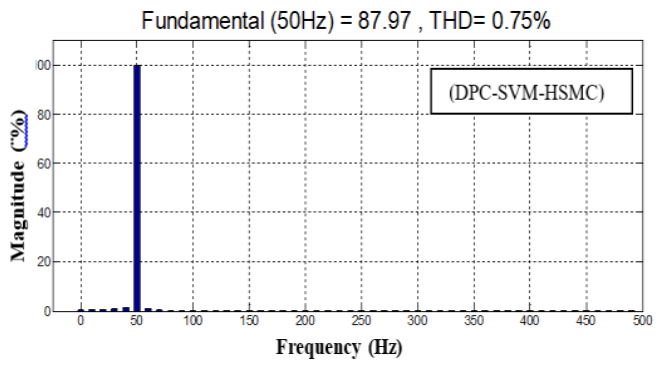

(c)

Figure 9. Robustness test; (a) output DC voltage; (b) THD of stator current for classical DPC; (c) THD of stator current for DPC-SVM-HSMC

\section{CONCLUSION}

In this work, we shown the principle of the traditional DPC technique and we proposed another topology (DPC-SVM-HSMC) for control of the output DC voltage of the converter attached in the PMSG side, the simulation results showed not only the efficiency of the proposed topology but also the robustness against the variation of the machine parameters. These results are judged by the appearance of the harmonics in the waveforms and the calculation of their THD values. The DPC-SVM-HSMC control technique illustrates a considerable reduction in ripple and THD value of the active power, reactive power waveforms and stator current, respectively.

\section{REFERENCES}

[1] C. L. Dang, L. Zhang, and M. X. Zhou, "Optimal Power Control Model of Direct Driven PMSG," Energy Procedia, vol. 12, pp. 844-848, 2011, doi: 10.1016/j.egypro.2011.10.111.

[2] G. Zhuo, J. D. Hostettler, P. Gu, and X. Wang, "Robust Sliding Mode Control of Permanent Magnet Synchronous Generator-Based Wind Energy Conversion Systems," Sustainability, vol. 12, no. 8, 2016, doi: 10.3390/su8121265.

[3] M. Zoghlami, A. Kadri, and F. Bacha, "Analysis and Application of the Sliding Mode Control Approach in the Variable-Wind Speed Conversion System for the Utility of Grid Connection," Energies, vol. 11, no. 4, 2018, doi:10.3390/en11040720.

[4] Y. Errami, M. Ouassaid, and M. Maaroufi, "Control of a PMSG based wind energy generation system for power maximization and grid fault conditions," Energy Procedia, vol. 42, pp. 220-229, 2013, doi: 10.1016/j.egypro.2013.11.022.

[5] E. Hossain, J. Hossain, N. Sakib, and R. Bayindir, "Modeling and Simulation of Permanent Magnet Synchronous Generator Wind Turbine: A Step to Micro-grid Technology," International Journal of Renewable Energy Research, vol. 7, no. 1, pp. 443-450, 2017.

[6] S. Shankar Naik, R. Kiranmayi, and M. Rathaiah, "Model Predictive Control of Back-to-Back Converter in PMSG Based Wind Energy System," International Research Journal of Engineering and Technology (IRJET), vol. 03, no. 11, Nov -2016.

[7] F. Amin, E. Bin Sulaiman, W. Utomo, H. Ali Soomro, M. Jenal, and R. Kumar, "Modelling and Simulation of Field Oriented Control based Permanent Magnet Synchronous Motor Drive System," Indonesian Journal of Electrical Engineering and Computer Science (IJEECS), vol. 6, no. 2, pp. 387-395, May 2017, doi: 10.11591/ijeecs.v6.i2.pp387-395.

[8] Y. C. Chang, H. C. Chang, and C. Y. Huang, "Design and Implementation of the Permanent Magnet Synchronous Generator Drive in Wind Generation Systems," Energies, vol. 11, no. 7, 2018, doi: 10.3390/en11071634. 
[9] R. Pilla, K. Santukumari, and K. B. Madhu Sahu: "Design and Simulation of the Control System for Inverte-fed Permanent Magnet Synchronous Motor Drive," Indonesian Journal of Electrical Engineering and Computer Science (IJEECS), vol. 12, no. 3, pp. 958-967, Dec. 2018, doi: 10.11591/ijeecs.v12.i3.pp958-967.

[10] F. Louar, A. Ouari, A. Omeiri, F. Senani, and A. Rahab, "Direct Power Control (DPC) of PMSG based Wind Energy Conversion System," 2015 4th International Conference on Electrical Engineering (ICEE), 2015, pp. 1-6, doi: 10.1109/INTEE.2015.7416794.

[11] F. Mazouza, S. Belkacema, I. Colakb, S. Dridc, and Y. Harbouchea, "Adaptive direct power control for double fed induction generator used in wind turbine," Electrical Power and Energy Systems, vol. 114, 2020, doi: 10.1016/j.ijepes.2019.105395.

[12] P. Gajewski and K. Pieńkowski, "Direct Torque Control and Direct Power Control of wind turbine system with PMSG," Przeglad Elektrotechniczny, vol. 92, no. 10, 2016.

[13] X. A. Shimonal and A. A. Jannie, "Direct Torque and Power control of PMSG based Wind Turbine system", Proceedings of 4th International Conference on Energy Efficient Technologies for Sustainability-ICEETS'18, St.Xavier's Catholic College of Engineering, TamilNadu, India, 5th to 7th April, 2018.

[14] J. Jose and A. Chitra, "Field Oriented Control of Space Vector Modulated Multilevel Inverter fed PMSM Drive," Energy Procedia, vol. 117, pp. 966-973, 2017, doi: 10.1016/j.egypro.2017.05.217.

[15] D. Hammoumi, C. El Bekkali, M. Karim, M. Taoussi, N. El Ouanjli, and B. Bossoufi, "Direct controls for wind turbine with PMSG used on the real wind profile of Essaouira-Morocco city," Indonesian Journal of Electrical Engineering and Computer Science (IJEECS), vol. 16, no. 3, pp. 1229-1239, Dec. 2019, doi: $10.22266 /$ ijies2021.0430.50.

[16] J. Zhang, Y. Zhang, B. Guo, and J. Gao, "Model Predictive Power Control of a PWM Rectifier for Electromagnetic Transmitters," Journal of Power Electronics, vol. 18, no. 3, pp. 789-801, May 2018, doi: 10.6113/JPE.2018.18.3.789.

[17] M. K. Yadav and A. K. Upadhayay, "Power Flow Control of Permanent Magnet Synchronous Generator Based Wind Energy Conversion System with DC-DC Converter and Voltage Source Inverter," International Journal of Electronic and Electrical Engineering, vol. 7, no. 8, pp. 803-814, 2014.

[18] M.S. Merzouga, H. Benalla, and L. Louze, "Sliding Mode Control (SMC) Of Permanent Magnet Synchronous Generators (PMSG)," Energy Procedia, vol. 18, pp. 43-52, 2012, doi: 10.1016/j.egypro.2012.05.016.

[19] N. Mamat, F. Yakub, S. Zaki Shaikh Salim, and M. Sukri Mat Ali, "Performance Comparison of Controllers for Suppressing the Structural Building Vibration," Indonesian Journal of Electrical Engineering and Computer Science (IJEECS), vol. 10, no. 2, pp. 537-544, May 2018, doi: 10.11591/ijeecs.v10.i2.pp537-544.

[20] N. M. Sarif, R. Ngadengon, H. A. Kadir, and M. H. A. Jalil, "Terminal sliding mode control on autonomous underwater vehicle in diving motion control," Indonesian Journal of Electrical Engineering and Computer Science (IJEECS), vol. 20, no. 2, pp. 798-804, Nov. 2020, doi: 10.11591/ijeecs.v20.i2.pp798-804.

[21] F. Mehedi, R. Taleb, A. Belhadj Djilali, and A. Yahdou, "SMC based DTC-SVM control of five-phase permanent magnet synchronous motor drive," Indonesian Journal of Electrical Engineering and Computer Science (IJEECS), vol. 20, no. 1, pp. 100-108, October 2020, doi: 10.11591/ijeecs.v20.i1.pp100-108.

[22] S. Wang, S. Li1, R. Gu1, L. Ma1, and M. Li1, "Adaptive sliding mode based active disturbance rejection control method for a direct-driven wind power conversion system," J. Eng, vol. 2019, no. 22, pp. 8365-8369, doi:10.1049/joe.2019.1082.

[23] İ. Yazıc1 and E. K. Yaylac1, "Discrete-time integral terminal sliding mode based maximum power point controller for the PMSG-based wind energy system," IET Power Electron, vol. 12, no. 14, pp. 3688-3696, 2019, doi: 10.1049/iet-pel.2019.0106.

[24] N. Bounasla and K. E. Hemsas, "Second Order Sliding Mode Control of a Permanent Magnet Synchronous Motor," 2013 14th International Conference on Sciences and Techniques of Automatic Control and Computer Engineering (STA), IEEE -1-4799-2954-2/13, 2013, doi: 10.1109/STA.2013.6783184.

[25] A. Merabet, "Cascade Second Order Sliding Mode Control for Permanent Magnet Synchronous Motor Drive," Electronics, vol. 8, no.10, p. 1508, doi: 10.3390/electronics8121508, 2019, doi: 10.3390/electronics8121508. 